\title{
A Saúde na Sociedade GlobaL ${ }^{*}$
}

Benjamin Pitcho ${ }^{(* *)}$

\section{RESUMO}

O trabalho analisa o conceito de saúde em uma sociedade global e em um cenário de globalização dos riscos. A maior dificuldade das sociedades democráticas é a de conciliar os valores de liberdade com as demandas da saúde pública que, muitas vezes, impõem restrições a estas mesmas liberdades. O Estado conta com inúmeros dispositivos para justificar medidas que violem as liberdades em periodos de epidemia e dois exemplos permitem entender as diferentes formas de combate às ameaças contra a saúde pública. As histórias das lutas contra a epidemia da SIDA e contra a pandemia gripal que, por terem modos distintos de contaminação, apresentam também demandas e resultados diferentes entre si. O dispositivo de luta contra a pandemia gripal demonstra a necessidade de violações às liberdades públicas; já o combate contra a disseminação do vírus HIV exige um reforço das liberdades, em benefício dos doentes.

\section{Palavras-chave}

Epidemia; França; Liberdade; Saúde; Sociedade.

\section{ABSTRACT}

This work evaluates the concept of health in a global society and in a scene of globalization of the risks. The biggest difficulty for the democratic

(*) Nota do editor: Trabalho apresentado durante o VII Seminário Internacional de Direito Sanitário, realizado na Faculdade de Saúde Pública da Universidade de São Paulo. São Paulo. Setembro de 2006.

${ }^{\star * *}$ Professor de Direito dos Negócios e Direito Sanitário na Universidade Paris VIII; especialista em Direito dos pacientes e da organização do sistema de saúde. E-mail: <pitcho.benjamin @ free.fr>. 
societies is how to conciliate the values of liberty with the demands of the public health which, many times, mean restrictions to these freedoms. Government counts on several instruments to justify measures which violate liberties in periods of epidemic and two examples allow to understand the different forms of fighting threats against the public health. Histories of the fights against the epidemic of the AIDS and the gripal pandemic that, due to their distinct ways of contamination, also present different demands and results. Fight against the gripal pandemic demonstrates the necessity of violations of the public freedoms; in other way, the combat against the dissemination of HIV virus demands a reinforcement of the freedoms, in benefit of the patients.

\section{Key words}

Epidemy; French; Liberty; Health; Society.

\section{I-INTRODUÇÃO}

A saúde na sociedade globalizada constitui-se em uma prerrogativa essencial, ao mesmo tempo em que, às vezes, é ameaçada. A saúde é essencial, em primeiro lugar, ao ser humano que, na sua individualidade, não pode se realizar sem uma garantia quanto a sua saúde e ao acesso aos tratamentos reconhecidos e eficazes.

A esse respeito, a Constituição francesa de 1958, por exemplo, reconheceu o direito à saúde como uma prerrogativa essencial ao indivíduo. Seu preâmbulo lembra a ligação do povo francês aos valores proclamados, notadamente, na Constituição de 1946, que, em seu art. 11, precisa que a nação "garante a todos, especialmente, à criança, à mãe e aos trabalhadores idosos, a proteção à saúde, a segurança material, o repouso e o lazer".

$\mathrm{O}$ art. L. 1110-1 do Código de Saúde Pública dispõe também, com relação a esse tema, que "o direito fundamental à proteção da saúde deverá ser aplicado por todos os meios disponíveis em benefício de todos".

Sob um outro prisma, o Direito internacional, em diversas declarações, insiste sobre a necessidade de se respeitar a saúde do indivíduo. A Declaração Universal dos Direitos dos Homens, adotada pela Organização das Nações Unidas (ONU), em 10 de dezembro de 1948, define em seu art. 25-1 que "Toda a pessoa tem direito a um padrão de vida capaz de assegurar a si e a sua familia saúde e bem-estar, inclusive alimentação, vestuário, habitação, cuidados médicos e os serviços sociais indispensáveis".

Se sua aplicabilidade é discutível na França, isso apenas demonstra que tal direito deve ser qualificado como essencial e que sua menção em textos internacionais permitem ligar a saúde e a sociedade global. 
Nenhuma definição eficaz de saúde, no entanto, advém do Direito interno. De novo, é a ONU, dentro da carta constitutiva da Organização Mundial de Saúde (OMS), que propõe uma definição de saúde como "não apenas ausência de saúde, mas completo bem-estar físico, social e mental".

Caso pretenda-se tratar da idéia de saúde em uma sociedade global, convém se interessar, por exemplo, com a integração de migrantes, trabaIhadores internacionais, refugiados; em uma palavra, todos os estrangeiros da sociedade. Com efeito, a apreensão do bem-estar mental remete em particular à integração. Noção difícil para nós, na França, como demostraram as recentes agitações populares de novembro de 2005 sobre o fracasso do projeto de integração, sejam quais forem a causa e os responsáveis e sem lembrar dos aspectos políticos.

Esta idéia será abandonada, mas sem que seja, de qualquer maneira, possivel de renunciar a uma idéia subjetiva de saúde. A partir de uma primeira definição, a saúde pode então ser apreendida como um julgamento feito pelo próprio indivíduo e seu estado físico.

A definição da OMS possui, e aqui se tem outra demonstração do elo entre a sociedade global e a proteção da saúde, o interesse em destacar os direitos fundamentais do individuo(1).

O projeto da ONU, do qual a OMS evidentemente faz parte, consiste em reunir de maneira irremediável e irrevogável a saúde e os direitos fundamentais. Em todos seus textos ${ }^{(2)}$, sob a tutela de seu ex secretário-geral Kofi Annan, a saúde não pode ser alcançada sem a evolução da democracia e sem 0 respeito aos direitos do indivíduo ${ }^{(3)}$.

De qualquer forma, a pertinência da noção de "sociedade global" deve ser considerada a fim de determinar sua transposição para a saúde. Uma primeira abordagem desta idéia é a sociológica que invoca as migrações. As sociedades seriam, então, membros de uma "vila planetária" na qual as fronteiras não existem e as diferenças são atenuadas para que se compreenda o pertencimento de todos a uma humanidade idêntica.

Em uma época na qual os conflitos são mais presentes do que nunca, que certos paises abertamente belicosos têm em seu poder armas nuclea-

(1) AJULEU, E. L'organisation mondiale de la santé. RFAS, p. 143, oct./dec. 1983. BEIGBEDER, Y. L'organisation mondiale de la santé. Paris: PUF, 1997. (Coll. Que sais-je?).

(2) Ver, por exemplo, www.who.int, que afirma que a agência dispõe de "três eixos principais de trabalho sobre a saúde e os direitos do homem: desenvolver uma abordagem de saúde e dos direitos do homem dentro da OMS; promover os interesses da saúde dos indivíduos relativos aos direitos internacionais do homem; incitar os governos a integrar os direitos do homem nas politicas e estratégias sanitárias".

(3) O caminho da ONU neste sentido é perfeitamente resumido por Kofi Annan que escreveu "desejo que a saúde não seja considerada como uma benção a se esperar, mas como um direito do homem pelo qual deve-se lutar", K. Annan, WORLD HEALTH ORGANIZATION. Disponivel em: $<h t t p: / / w w w . w h o . i n t . / e n>$. 
res, é fácil constatar que esse desejo revela mais uma utopia ${ }^{(4)}$ do que uma esperança, é mesmo um "tipo ideal", como disse Max Weber.

Convém destacar que nos discursos políticos, comerciais ou mesmo científicos, o termo "globalização" foi abandonado em benefício da expressão "sociedade global". Tal mudança significa evidentemente uma substituição de sentido, na medida em que por "sociedade global", o locutor deixa claro que a sociedade já é global. Contudo, tal afirmação não fica evidente e deve ser explicitada.

A internet quer nos fazer acreditar que a sociedade já está, em efeito, globalizada. Sua função primeira não é estritamente informativa, mas comercial e, dentro destas condições, todos podem constatar que a abolição das fronteiras não foi ainda absorvida e que continua difícil de ser aceita, por questões de livre comércio internacional, pois mantém-se a cobrança de taxas comerciais.

Com relação à saúde, pelo contrário, a idéia de uma sociedade já globalizada possui uma significação clara e, nem tanto pelo sentido positivo que poderia advir da saúde, mas pela generalização - a globalização dos riscos. A idéia de globalização, neste sentido, é mais do que verdadeira e não é, no entanto, nova. Os navios que trouxeram a peste para Gênova, Veneza ou Marselha fizeram parte deste processo de globalização. Pode ter havido mudanças na comunicação e ter aumentado a rapidez das mudanças. Os colonizadores espanhóis e portugueses, que transmitiram a sífilis e a gripe, participaram também da globalização dos riscos sanitários. A descoberta da América poderia mesmo ser considerada como o início da autêntica globalização.

Porém, os europeus não têm a mesma noção de globalização. Para eles, ela consiste em ameaças dos paises do Sul, vetores de doenças, de riscos e de perigo, por duas razões. Primeiro porque as populações de migrantes são portadoras de inúmeras moléstias das quais convém se imunizar. Este é, por exemplo, a razão de inquietudes no Marrocos que tenta se precaver da chegada das populações subsaarianas, que sobem a África em sua direção, a fim de prevenir o aparecimento de doenças.

Depois, porque existe uma variedade de perigos e moléstias que provêm do Sul para contaminar as populações européias, sem que haja intervenção das comunidades locais. As temerosas epidemias de SARS, da gripe aviária (H5N1), do HIV demonstraram a existência de uma tal percepção européia contra os fluxos de população, para os quais não existe outro remédio a não ser a separação destas.

(4) A raiz etimológica de utopia, como assumida por Thomas Moore, seu autor, consiste em criar uma confusão entre o eu-topos (o bom lugar) e o a-topos (o lugar que não existe). A sociedade global, assim vista, repete a evidência de tal ambigüidade. 
A idéia de globalidade expressa assim todo o sentido, pois, se ainda existem barreiras entre os homens, os virus, parasitas e doenças, por seu lado, não fazem distinção entre países, nem conhecem fronteiras ${ }^{(5)}$. Nas sociedades ditas democráticas, a dificuldade consiste, então, em permitir a manutenção da saúde, em um mundo no qual os riscos são globalizados, ao mesmo tempo em que afirma seus fundamentos democráticos liberais. Como conciliar os valores de liberdade com os imperativos da saúde pública, os quais, precisamente, impõem restrições a estas mesmas liberdades individuais?

Existe toda uma literatura tratando dessa dificuldade e ela é tão variada, como a maneira de apreender as coisas. Três obras maiores podem ser isoladas para analisar os modos de combate do Ocidente.

O primeiro é a busca de uma vítima expiatória, responsável por todos os males e que convém, então, erradicar metodicamente a fim de oferecer a salvação para a cidade. Cecil Roth escreveu uma obra sobre os judeus maronitas que testemunharam os sacrifícios de sua população, considerada responsável pelo mal que os atingira(6). Seus escritos demostram 0 velho hábito de apontar o outro como fonte de todos os males sanitários. Além disso, esse caminho impõe a busca da salvação em uma autoridade superior, exterior aos homens e aos meios humanos, que pune uma outra coletividade.

Já em Decameron, escrito em torno de 1350 por Bocage ${ }^{(7)}$, os jovens escolhem uma via radicalmente diferente. Quando Florença é contagiada pela peste, eles decidem sair da vila e se isolar para experimentarem toda sorte de depravações, ou ao menos, para falar sobre elas. A busca da salvação divina ficou assim caduca, em benefício de um hedonismo forçado. Uma vez que a vida deve prevalecer, viva-se portanto o mais intensamente possível. O materialismo praticado dessa maneira difere profundamente das teorias da igreja católica. O texto de Bocage foi expurgado por seus aspectos revolucionários.

Uma última abordagem, a mais atual, pode ser encontrada no trabaIho de Albert Camus em A Peste ${ }^{(8)}$. Assim que o mal é descoberto em Oran, o doutor Rambert, após o isolamento da cidade, faz um sacrifício exemplar. Ele conta com o apoio de Tarrou, filho do procurador, que morre ao final. $O$ interesse do romance, estritamente fictício, é triplo. A atitude do médico difere substancialmente daquela da igreja, de um lado, e do materialismo de Decameron, do outro. O herói conhece, por sua profissão, a precariedade da vida. Seu papel é o de conviver com as mesquinharias dos outros, a

(5) J. M. Hughes, pesquisador em Medicina, afirma que judiciosamente "a luta contra os micróbios é uma batalha entre a inteligência e os genes", Emerging Infectios Diseases, v. 1, 101, 1995.

(6) ROTH, C. Histoires des marranes. Liana Levi, rééd. 1997.

(7) BOCAGE. Le décaméron. Grands écrivains, rééd., 1987.

(8) CAMUS, A. La peste. rééd. Livre de poche, 1972. 
loucura dos cidadãos, para cumprir sua missão o melhor possível. Para reforçar a idéia de precariedade, o autor decide por matar a mulher do médico, mesmo ela não tendo sido contaminada, já que deixa a cidade antes da aparição da epidemia. A peste não a matou, mas outras vicissitudes acontecem e o médico, no contato permamente com o mal, não se abala. Ele é, enfim, em sua obra de cura e sacrifício, apoiado principalmente por um homem da lei. Mais exatamente, trata-se de um filho de um procurador, já que nessas situações, o médico e o jurista fazem efetivamente uma boa dupla.

Apesar das diferenças e dos anacronismos que surgem ao comparar essas visões, existe entre essas interpretações uma idéia idêntica. Em cada um desses episódios, aparece irremediavelmente o isolamento: forçado ou por escolha; há uma espécie de não contato com vida. Conseqüentemente, existe uma catarse própria destas situações, ou mais propriamente dito, uma liberação. O homem não é mais homem, ele torna-se quase um animal, familiarizado com seu instinto e abandonado pela civilização.

Há uma a-temporalidade nessas evocações de momentos de peste. Trata-se quase de uma guerra civil, na qual a licença é permitida, a baixeza esperada e o heroísmo de alguns previsível. Em todos esses casos, as liberdades individuais são ameaçadas e questionadas tanto pelas autoridades públicas, como pelos homens.

Resta definir o que é uma liberdade pública.

Por hipótese, consideramos que as liberdades públicas remetem às noções herdadas, especialmente, do século XVIII, que continuaram evoluindo. Elas são o "exercício sem entrave, garantido pelo Direito, de uma faculdade [autorizada] de participar da vida pública" (9). São essas as heranças da Revolução Francesa de 1789, da Declaração dos Direitos do Homem e do Cidadão, destinadas, em primeiro lugar, a proteger o indivíduo contra o Estado e, ainda, a propriedade, inviolável e sagrada, a religão, a resistência a opressão etc.

Hoje, pelo contrário, entendem-se as liberdades mais como a proteção dos indivíduos em sua própria essência, contra a intervenção de terceiros, por meio do reconhecimento do princípio da salvagarda da dignididade humana ${ }^{(10)}$, do respeito à integridade corporal(11), do direito à vida privada ${ }^{(12)}$,

(9) CORNU, G. (Dir.). Vocabulaire juridique. 6ème éd. Assoc. H Capitant. Paris: PUF, 1996, v. liberte. (10) Art. 16 do Código Civil, especificamente. O Conselho Constitucional confere um valor constitucional a esse princípio dentro das normas. V. C. constit., 27 juillet 1994, n. 94-343/344 DC, Lei relativo ao respeito do corpo humano e lei relativa à doação e uso de elementos e produtos do corpo humano, à assistência médica à procriação e ao diagnóstico do pré-natal, JO 29 juillet 1994; D. 1995, p. 237, note B. Mathieu; D. 1995, somm. p. 299, obs. L Favoreu; B. Edelman, Le Conseil constitutionnel et l'embryon, D. 1995, chron. p. 205.

(11) Art. 16-3 do Código Civil.

(12) Art. 9 do Código Civil. 
etc. Sejam quais forem as liberdades, "o nome dos direitos públicos individuais podem ter uma ressonância histórica ao evocar um estado ancião do Direito (a crença nos direitos naturais); pode conter uma alusão sociológica ao designar, entre os diversos direitos, aqueles aos quais uma crença política agregue um valor particular. Mas, juridicamente, nada permite caracterizar os direitos públicos individuais em uma massa de direitos colocados sob a garantia da lei e do juízo"(13).

Percebe-se, então, ser preferivel remeter ao termo de direitos fundamentais, mais do que liberdades públicas, para compreender, em uma sociedade democrática, as implicações a sua preservação provocadas pelos males gerados em situações de crises sanitárias.

Não é certo que a apreensão política tenha realmente evoluído desde a inquisição ou de Decameron e, assim, prosseguem as apostas na saúde dentro das sociedades globais que tentam manter seu caráter democrático.

Existem, de fato, numerosos dispositivos que permitem justificar as violações às liberdades em períodos de epidemia (tópico I deste artigo). Dois exemplos demonstram ainda a capacidade de adaptação do regime aplicável (tópico II).

\section{II - DISPOSITIVOS MAIS SIGNIFICATIVOS NA ADMINISTRAÇÃO DE EPIDEMIAS}

São inúmeros os regimes que permitem a uma autoridade administrativa dispor de poderes derrogatórios em caso de ameaças, sejam elas quais forem. Pode-se fazer uma relação desses pincipais dispositivos, utilizados em determinadas ocasiões para combater os riscos sanitários.

A teoria das circunstâncias excepcionais encontra justificação em duas decisões do Conselho de Estado, quais sejam: Dames Dol et Laurent ${ }^{(14)}$ et Heyriès ${ }^{(15)}$, que tratam da aplicação das liberdades públicas após a Primeira Grande Guerra Mundial.

Na decisão Dames Dol et Laurent, o juiz administrativo justifica as violações às liberdades públicas, nesses termos:

"Considerando que os limites de poder de polícia dos quais a autoridade pública dispõe para a manutenção da ordem e da segurança, seriam diferentes em tempos de paz e em um periodo de guerra, situação na qual os interesses da defesa nacional dão ao princípio de ordem pública uma extensão maior e exigem medidas mais rigorosas para a segurança pública; que compete ao juiz, sob o controle do qual

(13) VEDEL, G. Cours de droit Public. 3 ème année, 1949-1950, Les Cours de Droit, p. 168.

(14) CE, 28 février 1919, Dames Dol et Laurent, Rec. Lebon p. 208.

(15) CE, 28 juin 1918, Heyriès, Rec. Lebon p. 651. 
se exercem os poderes de polícia, de considerar, em sua apreciação, as necessidades geradas pelo estado de guerra, segundo as circunstâncias de tempo e de lugar, a categoria de indivíduos visados e a natureza dos perigos que devem ser evitados;

Considerando que no curso do ano de 1916, as condições nas quais as agitações das prostitutas se multiplicaram em Toulon e, em razão tanto da situação militar deste local, como da passagem incessante de tropas que seguiam ou chegavam do Oriente, apresentaram um caráter todo particular de tal gravidade, que a autoridade pública tinha $o$ dever de se preocupar em manter a ordem, a higiene e a salubridade e também de evitar o perigo que a freqüência de certos indivíduos suspeitos representava à defesa nacional; parece, então, que as medidas que são objeto do presente recurso foram necessárias para salvaguardar de maneira eficaz as tropas e o interesse nacional."

Sabe-se que a ordem pública, tradicionalmente, pela aplicação do art. L. 2212-2 do Código Geral de Coletividades Territoriais, tem relação com três objetos distintos: a tranquilidade pública, a segurança e a salubridade pública. A preservação da saúde, assim como da segurança nacional, justificam as medidas excepcionais que limitaram a liberdade individual dos governados. Do mesmo modo, a Constituição permite violações às liberdades públicas em situações agravadas, como diz, por exemplo, seu art. 16 que confere poderes excepcionais ao presidente da República, para proteger a nação.

"Na medida em que as instituições da República, a independência da nação, a integridade de seu território ou a execução de seus compromissos internacionais estejam ameaçadas de maneira grave e imediata e que o funcionamento regular dos poderes públicos constitucionais seja interrompido, o presidente da República tomará as medidas exigidas diante dessas circunstâncias, após consulta oficial ao primeiro-ministro, aos presidentes das assembléias, assim como ao Conselho Constitucional.

A nação será informada sobre essas medidas por um comunicado.

Essas medidas deverão ser inspiradas pela vontade de assegurar aos poderes públicos constitucionais, dentro de um prazo mínimo, os meios de cumprir sua missão. O Conselho Constitucional será consultado sobre o assunto.

O parlamento se reunirá em pleno direito.

A Assembléia Nacional não poderá ser dissolvida enquanto houver o exercício do poder excepcional."

Certamente parece audacioso evocar os poderes excepcionais do art. 16 em um quadro de proteção à saúde. O constituinte de 1958, evidentemente, não enxergava os perigos sanitários, mas sim, uma eventual situa- 
ção de guerra, especificamente dentro de um cenário de conflitos de independência das colônias francesas, que estavam em curso na época. Apesar desse desvio evidente do espírito da Constituição, é possivel considerar, em primeiro lugar que, conforme o texto, a continuidade das instituições da República poderia muito bem estar ameaçada em uma epidemia e, particularmente, em situação de uma guerra bacteriológica, se fosse ela terrorista.

Além do mais, como para todo regime se conferem prerrogativas derrogatórias à autoridade pública, fica sempre a mesma idéia de circunstâncias excepcionais que permitem a aplicação de medidas excepcionais. Por exceção, convém compreender aqui a oposição às liberdades públicas.

De qualquer maneira, o objetivo desses dispositivos está em, precisamente, apesar das violações, assegurar a preservação do Estado de Direito, o qual deverá ser imperativamente conservado e as autoridades públicas não agem, se não, por meio de uma habilitação de um texto particular.

Um outro regime correspondente a esta lógica, figura na Lei de 3 de abril de 1955, e permite ao Presidente declarar estado de urgência por decreto, no Conselho de Ministros. Foi proposto, inicialmente, para solucionar os problemas na Argélia. Recentemente, em novermbro de 2005, ele foi utilizado para acabar com a "violência urbana", sendo, em seguida prorrogado sem a censura do Conselho de Estado.

"o estado de urgência pode ser declarado sobre, ou em parte, do território metropolitano ou dos departamentos ultramar, seja em casos de perigo iminente, resultantes de atentados graves à ordem pública, ou em casos de eventos que apresentem, pela sua natureza e sua gravidade, o caráter de calamidade pública."

Entre os poderes envolvidos, o Ministério do Interior pode exigir residência fixa de uma pessoa "cuja atividade se mostrar perigosa para a segurança e a ordem pública". Enfim, parece ser necessário lembrar da existência de poderes derrogatórios atribuídos ao Ministério da Saúde, em caso de perigo sanitário grave.

Os arts. L. 3110-1, e os seguintes, do Código da Saúde Pública definem assim um regime totalmente derrogatório do Direito comum, o qual permite a criação de inúmeras violações às liberdades dos cidadãos, com o objetivo de proteger a saúde pública. Esta seqüência de artigos é interessante e está localizada em um título relativo à "vigilância epidemiológica", compondo também um capítulo preliminar intitulado "Ameaça Sanitária Grave".

O art. L. 3110-1 do Código de Saúde Pública dispõe ainda que:

"Em caso de ameaça sanitária grave que necessite de medidas urgentes, particularmente em caso de ameaça de epidemia, o ministro da Saúde, pode, por decisão fundamentada, adotar medidas para evitar e limitar as conseqüências das possiveis ameaças à saúde da popula- 
ção, dentro do interesse da saúde pública, proporcionais aos riscos e apropriadas às circunstâncias de tempo e localização."

Os estabelecimentos de saúde são, em seguida, convidados a participar dessas medidas, uma vez que o art. L. 3110-7, do mesmo Código, prevê que:

"Todo estabelecimento de saúde contará com um dispositivo de crise, denominado plano branco do estabelecimento, que lhe permitirá mobilizar imediatamente os meios de toda a natureza dos quais ele disponha, em caso de afluxo de pacientes ou de vítimas, ou para enfrentar uma situação sanitária excepcional."

De qualquer forma, se os Planos Brancos forem ineficazes, o art. L. 3110-8 lembra, por seu lado, que:

"Se o afluxo de pacientes ou de vítimas, ou a situação sanitária as justifiquem, o representante do Estado no departamento poderá proceder a requisições necessárias de todos os bens e serviços, e particularmente, requerer o serviço de todo profissional de saúde, independentemente de seu modo de exercício, e de todo o estabelecimento de saúde ou estabelecimento médico-social, dentro de um quadro do dispositivo denominado plano branco ampliado.

Estas requisições podem ser individuais ou coletivas. Elas serão declaradas por meio de uma decisão fundamentada que fixará a natureza das prestações requeridas, a duração da medida de requisição e ainda as modalidades de sua aplicação. O representante do Estado no departamento poderá providenciar a execução destas por ofício.

A indenização das pessoas requisitadas e dos estragos causados pela situação fixa-se dentro das condições previstas pela legislação $n$. 59-63 de 6 de Janeiro de 1959, relativa às requisiçõpes de bens e serviços."

O certo é que esta disposição, felizmente, foi completada por um texto específico do Código da Propriedade Intelectual que autoriza o ministro da Indústria a violar todos os registros depositados, em caso de ameaça à saúde pública, mais especificamente.

As graves ameaças à saúde equivalem a uma causa de exoneração de toda responsabilidade dos profissionais de saúde, sendo que os danos causados pelas ações realizadas, durante o período de ameça grave, serão indenizados pela solidariedade nacional.

Se as equipes sanitárias não estão preparadas, o jurista lhes equipará perfeitamente para validar a renúnica a todas as liberdades públicas. Além do que, é um traço do positivismo constatar que se o ordenamento jurídico é respeitado, as violações são justificadas, renovando de tal maneira o eterno debate entre legalidade e legitimidade. 
Aí está, definitivamente, o centro desta problemática: não são tanto as situações de urgência que interessam ao jurista, mas sim os poderes que poderão ser utilizados.

\section{III - COMPARAÇÃO DE DOIS EXEMPLOS: O HIV E A EPIDEMIA DE GRIPE AVIÁRIA}

Dois exemplos permitem compreender a adaptação do dispoitivo de combate contra as ameaças sanitárias, segundo sua origem. A história da luta contra a epidemia da SIDA e contra a pandemia gripal que, por seus modos de contaminação específicos, têm efeitos fortemente diferenciados.

\section{A - Os dispositivos de luta}

No momento em que o dispositivo de luta contra a pandemia gripal demonstra a necessidade de violações às liberdades públicas, a história do combate contra a disseminação do virus HIV exige que se trate do reforço das liberdades, o qual vem sendo realizado em benefício dos doentes.

\section{O dispositivo de luta contra o vírus HIV}

O que dizer sobre a luta contra a disseminação do vírus HIV que já não tenha sido dito na França e no mundo? Esta pandemia está perfeitamente documentada, compilada e rastreada por inúmeras instituições sanitárias, especializadas ou não, nacionais e internacionais ${ }^{(16)}$.

(16) Para uma bibliografia não exaustiva v. Pour une anthropologie de l'épidémie, v. J.-P. Baud, SIDA et liberté. La régulation d'une épidémie dans un Etat de droit, (ss dir.) E. Heilmann, Actes Sud, 1991; Pour les problèmes de contaminations post-transfusionnelles: Y. Lambert-Faivre, L'indemnisation des victimes post-transfusionnelles du sida: hier, aujourd'hui et demain..., RTD civ. 1993, p. 1; M.-D. Gmerk, Histoire du sida, début et origine d'une pandémie actuelle, Plon, 1989; M. Lucas, Transfusion sanguine et sida en 1985, Rapp. IGAS, septembre 1990; D.-C. Lambert, Le coût mondial du sida, CNRS, 1992; J. Foyer et L. Khaïat (ss dir.), Droit et sida: comparaison internationale, CNRS., 1994; J.-C. Thoenig et M. Setbon, L'action collective organisée face au risque: d'un cadre conceptuel au cas risque-sida, CNRS, 1995; C. Manuel, J.-L. San Marco, Sida: les enjeux éthiques, Doin, 1994; M.-A. Hermitte, Le sang et le droit: essai sur la transfusion sanguine, Seuil, 1996. Pour la responsabilité sanitaire: D. Berra, Responsabilités, indemnisation des dommages du sida, Action et rech. soc. octobre-décembre 1989; H. Margeat, Séropositivité, sida et jurisprudence, Gaz. Pal. 13 octobre 1991, p. 6; P. Jourdain, Responsabilité civile et contamination par le virus du sida à la suite de transfusions, RTD civ. 1992, p. 117; C. Delpoux, Contamination par transfusion sanguine: jurisprudence, loi et assurance, RGAT. 1992.25; M.-L. Morançais-Demeester, Contamination par le virus du sida: responsabilité et indemnisation, D. 1992, chron. p. 189; A. Holleaux, Transfusion sanguine, séropositivité et indemnisation des préjudices résultant de la contamination par le virus du sida, RD sanit. soc. 1992, p. 555; C. Debouy, La responsabilité de l'administration française du fait de la contamination par le virus du sida, JCP 1993, I, 3646; L. Dubouis, Sida et transfusion sanguine: I'assouplissement des conditions classiques de mise en jeu des professions de santé, RD sanit. soc. 1991, p. 574; F. Memmi, Sida et responsabilité civile, Gaz. Pal. 25 avril 1993, p. 2; H. Margeat, Sang et droit: l'indemnisation des 
Três exemplos demonstram o favorecimento em benefício dos pacientes, pelo menos com relação à proteção jurídica, em virtude do HIV.

Em primeiro lugar, e ao contrário dos dispositivos ainda recentemente qualificados de "fluxo social" pelo legislador, particularmente o alcoolismo, as doenças mentais, a tuberculose ou a sífilis, o HIV jamais foi objeto de um tratamento obrigatório.

Além disso, o art. L. 1111-2 do Código de Saúde Pública lembra que " $A$ vontade de um indivíduo de não conhecer um diagnóstico ou prognóstico deve ser respeitada, a menos que terceiros possam ser expostos a um risco de transmissão". A pessoa pode, então, não ser informada de sua patologia, sobre sua ordem expressa, mas desde que não haja nenhum risco de contaminação de terceiros.

Nesta situação, este terceiro não se beneficia de nenhuma informação, já que será o doente, e apenas ele - especificamente pelo fato da obrigação penal do segredo médico - que será informado. Esta terceira pessoa fica então exposta ao risco de contaminação, segundo a vontade inequívoca do doente.

Enfim, pensando no HIV, diversos dispositivos prevêem, quer sejam legislativos ou convencionais, a possibilidade legal de pessoas doentes se beneficiarem de um seguro.

A pandemia gripal, pelo contrário, revela um conjunto de prerrogativas, à disposição das autoridades públicas responsáveis pelo seu combate, claramente mais coercitivas.

\section{O plano de luta contra a pandemia gripal}

O governo disponibilizou um site na internet que traz o texto completo do plano elaborado para combater de maneira eficaz o desenvolvimento de uma pandemia gripal(17). Constata-se, sistematicamente, que diferentes níveis de ações são apresentados neste plano, de acordo com a importância da ameaça e de seus efeitos esperados ou presentes.

Assim, foram previstas medidas de vigilância epidemiológica, mas também sobre as aves selvagens ou de criações. Também, em caso de

victimes, Gaz. Pal. 6-7 août 1993, p. 2; F.-J. Pansier, Transfusion et religion, Gaz. Pal. 11-12 janvier 1995, p. 24; C. Rousseau, L'évaluation médico-légale en droit commun du dommage en rapport avec une séropositivité HIV., Rev. fran. domm. corp. 1993-3, p. 311; J.-S. Bergé, Risque et faute dans la contamination post-transfusionnelle, Gaz. Pal. $12-13$ juillet 1996, p. 13; S. Gromb, Les problèmes médicaux légaux de la transfusion sanguine, ESKA, 1997; M. Lebeau, Responsabilité et contaminations post-transfusionnelles, Gaz. Pal. 16-17 juin 1999, p. 35; C. Moniollet, Responsabilité et indemnisation à l'égard des personnes contaminées par le virus du sida lors de transfusions sanguines, RD sanit. soc. 1999 , p. 91.

(17) Republique Française. Disponível em: <http://www.grippeaviaire.gouv.fr/>. 
ameaça, medidas de confinamento das criações poderão ser, pontual e localmente, declaradas; o mesmo com relação às restrições de venda. Além disso, todas as pessoas que tenham tido contato com os pássaros portadores, ou potencialmente portadores, do vírus $\mathrm{H} 5 \mathrm{~N} 1$ poderão sofrer restrições a sua cirulação.

E, com o progresso das ameaças e perigos, desde que uma ave esteja contaminada no meio de uma criação, é possível decidir por sua morte, violando o direito de propriedade e, depois, pela destruição dos cadáveres. Evidentemente, e por aplicação inequívoca do Código Civil, os animais são tratados como coisa; hipoteticamente, são tratados como produto e não mais como seres vivos. Para prevenir um risco, a criação toda, mesmo sã, pode ser erradicada.

Em uma situação de perigo para o homem, o ministro da Saúde pode decidir por um tratamento automático das pessoas que tiveram contato com as aves, o qual será constituído de controle de circulação, tratamentos "terapêuticos", seguidos de busca ativa de pessoas e distribuição de kits de prevenção; porém, sem o porte obrigatório.

Enfim, dando continuidade à gradação de violações às liberdades públicas, em situação de crise, poderão ser declaradas medidas de requisição de médicos aposentados e de estudantes de Medicina, para enfrentar o aumento das atividades e mesmo declaradas todas as restrições à liberdade de ir e vir. Estratégias de tratamentos privilegiados serão iniciadas em paralelo, particularmente, ao tratamento prioritário de certas pessoas, tais como trabalhadores da área de infra-estrutura, cuja interrupção das atividades pode ser perigosa (centrais nucleares, química etc.), da área médica e aqueles que participam da preservação das funções militares e estratégicas da nação.

Serão abordadas agora as diferenças do tratamento dado às duas epidemias.

\section{B - Uma luta diferenciada}

As diferenças de tratamento jurídico entre essas duas epidemias podem ser triplamente justificadas.

Inicialmente, é incontestável que a prevenção contra a disseminação do HIV funcionou, haja vista o nível de adesão das pessoas. Também as autoridades públicas são incumbidas de preservar a escolha do indivíduo e evitar, a todo o preço, de utilizar algum caráter infamante ou de desvalorização da doença como exemplo. O fracasso precoce da prevenção pode ser explicado, particularmente pelo real ostracismo súbito das primeiras vítimas.

No caso da pandemia gripal, ao contrário, o caráter chocante esperado da contaminação, a impossibilidade de prever os modos de proteção e a 
inutilidade do recurso à boa vontade de cada um, justificaram a possivel criação de medidas coercitivas.

Respectivamente, o modo de contaminação destas duas doenças corresponde, em um primeiro caso, a uma tentativa de demonstrar a responsabilidade individual de cada um e a necessidade de reflexão sobre mudanças de comportamento individual; e, em um segundo caso, a prevenção ao inverso de uma transmissão contra a qual todos os meios disponiveis são ineficazes.

Em seguida, na condução da análise da proporcionalidade, nas duas situações, o interesse individual é inevitavelmente sacrificado em benefício da preservação do bem público. Quer se trate da destruição de uma criação de aves por um profissional - o que constitui um prejuízo financeiro enorme - ou da interdição de tratamento no hospital, caso a pandemia se torne severa, o governo tentará manter um balanço efetivo entre as duas lógicas contraditórias.

Enfim, se as estratégias são bem diferenciadas, em razão dos modos de contaminação, profundamente distintos, parece que, nos dois casos, uma reflexão jurídica continua necessária.

Todos esses cenários de epidemia consistem, em efeito, como já observado, em permitir o questionamento dos princípios da legalidade. A característica primeira do estado de exceção reside exatamente em tal questionamento. Convém determinar, então, em todo caso, os limites da necessidade de se impor medidas, pois, se a aparência de legalidade é preservada pela criação de regimes especiais, a democracia continua a impor também a manutenação de certas 1 ıerdades fundamentais. A análise desses regimes derrogatórios opera, então, uma confusão entre a manutenção de uma sociedade, de um lado, e a preservação da ordem democrática, de outro. Um equilibrio certamente difícil de ser alcançado em situações de crise.

\section{REFERÊNCIAS}

AJULEU E. L'organisation mondiale de la santé. RFAS oct.-déc. 1983.

BEIGBEDER, Y. L'organisation mondiale de la santé. Paris: PUF, 1997. (Coll. Que sais-je).

Disponivel em: www.who.int.

Emerging Infectios Diseases, 1, 101, 1995.

BOCAGE. Le décaméron. Grands écrivains, rééd. 1987.

CAMUS, A. La peste, rééd. Livre de poche, 1972.

CE, 28 février 1919, Dames Dol et Laurent, Rec. Lebon. p. 208.

CE, 28 juin 1918, Heyriès, Rec. Lebon. p. 651. 
CORNU, G. (Dir). Vocabulaire juridique. Assoc. H Capitant, PUF, $6^{\text {ème éd., }}$ 1996, v. liberté.

REPUBLIQUE FRANÇAISE. World Health Organization. disponivel em: $<$ http:www.who.int./en>

ROTH, C. Histoires des marranes. Liana Levi, rééd. 1997.

VEDEL, G. Cours de Droit public. $3^{\text {ème }}$ année, 1949-1950, Les cours de Droit, p. 168.

Disponivel em: <http://www.grippeaviaire.gouv.fr/>.

\section{VERSÃO EM FRANCÊS}

\section{La Santé Dans la Société Globale}

Benjamin Pitcho(*)

La santé dans la société globale constitue une prérogative essentielle en même temps que, parfois, menacée. Elle est essentielle en premier lieu, à l'être humain qui, pris dans son individualité, ne peut efficacement se réaliser sans une garantie quant à sa santé ni sans un accès aux soins reconnu et efficace.

A ce titre, la Constitution française de 1958 reconnaît, par exemple, à l'individu, le droit à la santé comme une prérogative essentielle. Son préambule rappelle l'attachement du peuple français aux valeurs proclamées notamment dans la Constitution de 1946 qui, en son article 11, précise que la Nation "garantit à tous, notamment à l'enfant, à la mère et aux vieux travailleurs, la protection de la santé, la sécurité matérielle, le repos et les loisirs".

L'article L. 1110-1 du Code de la santé publique dispose aussi à cet effet que "le droit fondamental à la protection de la santé doit être mis en cuvre par tous moyens disponibles au bénéfice de toute personne".

Par ailleurs, le droit international, dans diverses déclarations, insiste sur le nécessaire respect de la santé de l'individu. La Déclaration Universelle des Droits de l'Homme, adoptée par l'ONU le 10 décembre 1948, précise

(*) Maître de conférences et professeur de droit des affaires e de droit de la santé à l'Université Paris 8; spécialiste dans les questions relatives aux droits des patients et d'organisation du système de santé. E-mail: <pitcho.benjamin@free.fr>. 
dans son article 25-1 que "toute personne a droit à un niveau de vie suffisant pour assurer sa santé, son bien-être et ceux de sa famille, notamment pour l'alimentation, l'habillement, le logement, les soins médicaux ainsi que pour les services sociaux nécessaires".

Si son applicabilité est discutable en France, il n'en demeure pas moins qu'un tel droit peut être qualifié d'essentiel et que sa place dans un texte international permet de relier la santé et la société globale.

Aucune définition efficace de la santé n'est pourtant fournie en droit interne. C'est à nouveau l'ONU, dans la Charte constitutive(1) de l'OMS, qui a pris soin de proposer une définition de la santé comme "le plus complet état de bien-être physique social et mental, et pas seulement l'absence de maladie" ${ }^{(2)}$.

Si l'on devait aborder l'idée de santé dans la société globale, il conviendrait donc de s'intéresser, par exemple, à l'intégration des migrants, des travailleurs internationaux, des réfugiés, en un mot de tous les étrangers de la société.

Car, en effet, l'appréhension du bien-être mental renvoie en particulier à l'intégration. Notion difficile pour nous en France, dans laquelle, sans évoquer la politique, les récentes émeutes de novembre 2005 ont montré l'échec du projet d'intégration, quelle qu'en soit la cause et le responsable.

Cette idée sera abandonnée, mais sans qu'il soit toutefois possible de renoncer à une idée de subjectivité dans la santé. Dans une première définition, la santé peut donc être appréhendée comme un jugement porté sur soi-même et son état physique.

La définition de l'OMS possède, outre la démonstration de la pertinence du lien entre la société globale et la protection de la santé, l'intérêt de maximiser les droits fondamentaux de la personne ${ }^{(3)}$.

Le projet de l'ONU, dont l'OMS dépend évidemment, consiste à lier de manière irrémédiable et irrévocable la santé et les droits fondamentaux. Dans tous ces textes ${ }^{(4)}$, sous la plume de son Secrétaire Général Kofi ANNAN,

(1) 'L'OMS, agence des Nations Unies spécialisée dans la santé, a été créée le 7 avril 1948. L'objectif de l'OMS, comme défini dans sa Constitution, est l'atteinte par tous les peuples du niveau. (2) "Health is defined in WHO's Constitution as a state of complete physical, mental and social wellbeing and not merely the absence of disease or infirmity"; cette définition figure dans le Préambule de la Constitution de l'OMS adoptée par la Conférence Internationale sur la santé, New York, 19-22 juin 1946, signée par les représentants de 61 États et entrée en vigueur le 7 avril 1948, Official Records of the World Health Organisation, n. 2, p. 100. WORLD HEALTH ORGANIZATION. Disponivel em: <http://www.who.int./en>.

(3) AJULEU, E. L'organisation mondiale de la santé. RFAS, p. 143, oct./dec. 1983; BEIGBEDER, Y. L'organisation mondiale de la santé. Paris: PUF, 1997. (Coll. Que sais-je?).

(4) V. par ex. WORLD HEALTH ORGANIZATION. Disponivel em: <http://www.who.int./en>, qui affirme que l'agence dispose de "trois axes majeurs de travail sur la santé et les droits de l'homme: développer une approche de la santé et des droits de l'homme au sein de l'OMS; promouvoir les intérêts de la santé dans les sujets relatifs aux droits internationaux de l'homme; inciter les gouvernements à intégrer les droits de l'homme dans les politiques et stratégies sanitaires." 
la santé ne peut être obtenue sans la progression de la démocratie ni le respect des droits de l'individu(5).

C'est toutefois la pertinence de la notion de "société globale" qui doit être prise en considération afin de déterminer sa transposition dans la santé. Une première approche de cette idée réside dans celle du sociologue. Elle fait appel à des migrations.

Nos sociétés seraient donc membres d'un "village planétaire" dans lequel les frontières sont abolies, les différences atténuées afin de rendre compte de l'appartenance de tous à une identique humanité.

A une époque dans laquelle les conflits demeurent plus que jamais présents, que certains pays ouvertement belliqueux réussissent à se doter d'une arme nucléaire, il apparaît plus qu'aisé de constater que ce souhait relève plus d'une utopie ${ }^{(6)}$ que d'un souhait, voire même d'un idéal-type comme l'exprimait Max Weber.

Il convient à ce titre de remarquer que dans les discours politiques, commerciaux voire scientifiques, le terme de "globalisation" a été abandonné au profit de l'expression "société globale". Or un tel changement opère bien évidemment une substitution de sens, dans la mesure où par "société globale", le locuteur laisse comprendre que la société est désormais déjà globale.

Une telle affirmation ne reste pourtant pas évidente, mais elle doit, à nouveau être explicitée.

L'Internet voudrait nous faire croire que la société est en effet déjà globalisée. Sa fonction première ne demeure cependant pas strictement informative, mais bien commerciale et, dans ces conditions, tous peuvent constater que l'abolition des frontières n'est pas encore achevée. II demeure difficile, pour des raisons fiscales d'acheter librement en dehors de ses frontières nationales, puisque toutes les taxes demeurent plus que jamais applicables.

Pour la santé au contraire, l'idée de société déjà globalisée possède une signification évidente. Et ce n'est pas tant au sens du bénéfice que tous peuvent retirer de la santé que par la généralisation - la globalisation - des risques créés.

(5) La démarche de l'OMS est en ce sens parfaitement résumée par K. Annan, Secrétaire général de l'ONU, qui écrit que "c'est mon souhait que la santé ne soit finalement pas considérée comme une bénédiction à souhaiter, mais comme un droit de l'homme pour lequel il faut se battre" ("It is my aspiration that health will finally be seen not as a blessing to be wished for; but as a human right to be fought for "), K. Annan, WORLD HEALTH ORGANIZATION. Disponivel em: <http://www.who.int./en>. (6) La racine étymologique de l'utopie, telle qu'assumée d'ailleurs par Th. More son auteur, consiste à opérer une confusion entre l'eu-topos (le lieu du bonheur) et l'a-topos (le lieu qui n'existe pas). La société globale, ainsi envisagée, répète à l'évidence une telle ambiguïté. 
L'idée de globalisation est à ce titre plus que véridique. Elle n'est cependant pas réellement nouvelle. Les navires qui ramènent la peste à Gênes, Venise ou Marseille participent à la globalisation. C'est simplement l'information qui a peut-être, de ce point de vue, changé, ainsi que la rapidité des échanges.

De même, les colonisateurs espagnols et portugais qui apportent la syphilis et la grippe participent eux aussi à la globalisation des risques sanitaires. En réalité, la découverte de l'Amérique pourrait même être considérée comme le début authentique de la globalisation.

Pourtant, les Européens possèdent toujours la même approche de la globalisation, consistant en un Sud menaçant, vecteur de maladies, de dangers et de risques, à double tire.

D'abord les populations de migrants apportent de nombreuses maladies dont il convient de se prémunir. Tel est par exemple le sens des inquiétudes actuelles, au Maroc, qui tente de se prémunir contre la remontée de populations subsahariennes vers le Royaume afin de prévenir l'émergence de maladies.

C'est ensuite la multitude de dangers et de maladies qui proviennent du Sud pour venir infester les populations européennes, sans l'intervention des populations locales. Les épidémies redoutées de SRAS, la grippe aviaire (H5N1), le HIV démontrent à l'envi l'existence d'une telle perception européenne contre des fléaux pour lesquels il n'existe pas d'autre remède que la séparation des populations.

L'idée de globalité possède alors tout son sens, car si des barrières demeurent entre les hommes, en revanche les virus, parasites et maladies, pour leur part, ne distinguent pas entre les pays et ne connaissent aucune frontière $\mathrm{e}^{(7)}$.

La difficulté consiste donc, dans des sociétés dites démocratiques, à permettre le maintien de la santé dans une société pour laquelle les risques sont globalisés, en maintenant ses fondements démocratiques libéraux.

Comment concilier les valeurs de liberté avec les impératifs de santé publique qui, précisément, imposent la restriction de ces mêmes libertés individuelles?

II existe toute une littérature qui fait part de cette difficulté. Celle-ci est variée autant que typique de la manière d'appréhender les choses.

Trois exemples paroxystiques peuvent être isolés afin de constater les modes de luttes mis en œuvre en Occident.

(7) HUGUES, J. M. chercheur en médecine, affirmait ainsi judicieusement que "la lutte contre les microbes est une bataille entre l'intelligence et des gènes", Emerging Infectios Diseases, v. 1, 101, 1995. 
Le premier mode consiste à rechercher une victime expiatoire, chargé de tous les maux et qu'il convient donc d'éradiquer méthodiquement afin d'offrir le salut de la Cité. Cecil Roth a écrit un ouvrage sur les Marranes qui témoigne des sacrifices de ces populations considérées responsables du mal(8).

Ces récits démontrent ainsi qu'une vieille habitude consiste à désigner l'autre comme source de tous les maux sanitaires. De plus, cette démarche impose la recherche du salut dans une autorité supérieure, extérieure aux hommes et aux moyens humains, qui punit une autre collectivité.

Dans le Décameron écrit vers 1350 par Boccace ${ }^{(9)}$, de jeunes personnes choisissent une voie radicalement différente. Alors que Florence est frappée par la peste, ceux-ci décident de quitter la ville, s'isoler pour se livrer à toutes sortes de débauches, ou du moins les raconter.

La quête du salut divin devient caduque, au profit d'un hédonisme forcené. Puisque la vie doit en effet prévaloir, il convient de vivre le plus intensément possible. Le matérialisme ainsi mis en œuvre diffère profondément des théories de l'église catholique. Le texte de Boccace fut d'ailleurs largement expurgé pour ses aspects révolutionnaires.

Une dernière approche, la plus actuelle, peut être trouvée sous la plume d'Albert Camus dans La peste(10). Alors que le mal est découvert à Oran le Dr. Rambert, à la suite de l'isolement de la ville, fait preuve d'un dévouement exemplaire. II est assisté par Tarrou, fils du procureur qui va pour sa part mourir à la fin.

L'intérêt du roman, strictement fictif, est triple. L'attitude du médecin diffère substantiellement de celle de l'Eglise d'une part et du matérialisme affiché dans Le décameron d'autre part.

Le héros connaît, par profession, la précarité de la vie. Son rôle consiste dès lors à composer avec les mesquineries des autres, la folie des concitoyens afin de remplir sa mission du mieux possible.

Afin de renforcer ensuite cette idée de précarité, l'auteur choisit de faire mourir la femme du médecin, alors même que celle-ci avait quitté la ville avant l'apparition de l'épidémie. La peste ne l'a donc pas tuée, mais d'autres vicissitudes entraînent son décès alors que, par comparaison, le médecin au contact permanent du mal demeure indemne.

Il est enfin, dans son œuvre de guérison et de dévouement, principalement assisté par un homme de loi. Plus exactement, il s'agit du fils du procureur car, dans ces situations, le médecin et le juriste font effectivement bon ménage.

(8) BOCAGE. Le décaméron. Grands écrivains, rééd., 1987.

(9) Id. Ibid.

(10) CAMUS, A. La peste, rééd. Livre de poche, 1972. 
Malgré les différences et les anachronismes consistant à comparer ces visions, il existe entre ces interprétations idée identique. Lors de chacun des ces épisodes en effet l'isolement apparaît immanquablement: forcé ou choisi, il y a une espèce de mise hors contact de la vie.

Poursuivant, il existe une catharsis propre à ces instants, à proprement parler, un déchaînement. L'homme n'est plus homme, il redevient presque animal, hanté par son instinct et abandonné par la civilisation.

II y a une a-temporalité dans ces évocations des moments de peste. II s'agit presque d'une une guerre civile, dans laquelle la licence est permise, la bassesse attendue et l'héroïsme de certains prévisible.

Dans tous ces cas, les libertés individuelles sont menacées et remises en cause tant par les autorités publiques que par les hommes. Encore faut-il préciser ce qu'est une liberté publique.

Par hypothèse, nous considèrerons que les libertés publiques font appel à des notions héritées du XVIII'ème siècle notamment et dont la conquête a été continuée depuis. Elles consistent en "l'exercice sans entrave garanti par le Droit d'une faculté [permettant] de participer à la vie publique"(11).

Ce sont celles héritées de la Révolution française de 1789, de la Déclaration des droits de l'homme et du citoyen, destinées, en premier lieu, à protéger l'individu contre l'État. Ainsi de la propriété, inviolable et sacrée, de la religion, de l'égalité, de la résistance à l'oppression, etc.

Aujourd'hui au contraire, les libertés s'entendent davantage de la protection des individus, dans leur essence même, contre l'intervention des tiers privés, au travers de la reconnaissance du principe de sauvegarde de la dignité de la personne humaine ${ }^{(12)}$, du respect de l'intégrité corporelle ${ }^{(13)}$, du droit à la vie privée ${ }^{(14)}$, etc.

Quelles que soient ces libertés, "le nom de droits publics individuels peut avoir une résonance historique en évoquant un état ancien du droit (la croyance aux droits naturels); il peut contenir une allusion sociologique en désignant parmi les divers droits ceux auxquels une croyance politique attache une valeur particulière. Mais, juridiquement, rien ne permet de caractériser les droits publics individuels dans la masse des droits placés sous la garantie de la loi et du juge"(15).

(11) CORNU, G. (Dir.). Vocabulaire juridique. 6ème éd. Assoc. H Capitant. Paris: PUF, 1996, v. liberte. (12) Article 16 du Code civil, notamment. La Conseil constitutionnel confère une valeur constitutionnelle à ce principe au sein de la hiérarchie des normes. V. C. constit., 27 juillet 1994, n. 94-343/344 DC, Loi relative au respect du corps humain et loi relative au don et à l'utilisation des éléments et produits du corps humain, à l'assistance médicale à la procréation et au diagnostic prénatal, JO 29 juillet 1994; D. 1995, p. 237, note B. Mathieu; D. 1995, somm. p. 299, obs. FAVOREU, L.; EDELMAN, B., Le Conseil constitutionnel et l'embryon, D. 1995, chron. p. 205.

(13) Article 16-3 du Code civil.

(14) Article 9 du Code civil.

(15) VEDEL, G. Cours de droit public. 3 ème année, 1949-1950, Les Cours de Droit, p. 168. 
II apparaît donc préférable d'invoquer le terme de droits fondamentaux, plutôt que libertés publiques, afin de constater les atteintes que les situations de crises sanitaires peuvent imposer à leur maintien dans une société démocratique.

II n'est finalement pas certain que l'appréhension politique ait tellement évolué depuis l'inquisition ou le Décaméron et telle demeure, en définitive, l'enjeu de la santé dans les sociétés globales qui tentent de maintenir leur caractère démocratique.

Il existe en effet de très nombreux dispositifs permettant de justifier les atteintes aux libertés dans les périodes d'épidémie (I). Deux exemples de lutte contre des épidémies différentes démontrent ainsi la capacité d'adaptation du régime applicable (II).

\section{I - LES DISPOSITIFS LES PLUS SIGNIFICATIFS POUR LE TRAITEMENT DES EPIDEMIES}

Nombreux sont les régimes qui permettent à l'autorité administrative de disposer de pouvoirs dérogatoires en cas de menaces, quelle qu'elle soit. Une liste de ces principaux dispositifs, qui peuvent le cas échéant trouver à s'appliquer en matière de menace sanitaire, peut ainsi être dressée.

La théorie des circonstances exceptionnelles trouve sa justification dans deux arrêts du Conseil d'État, les décisions Dames Dol et Laurent ${ }^{(16)}$ et Heyriès ${ }^{(17)}$. Ces deux décisions concernent l'application des libertés publiques lors du premier conflit mondial.

Dans l'arrêt Dames Dol et Laurent, le juge administratif justifie les atteintes aux libertés publiques en ces termes:

"Cons. que les limites des pouvoirs de policé dont l'autorité publique dispose pour le maintien de l'ordre et de la sécurité, ne sauraient être les mêmes dans le temps de paix et pendant la période de guerre où les intérêts de la défense nationale donnent au principe de l'ordre public une extension plus grande et exigent pour la sécurité publique des mesures plus rigoureuses; qu'il appartient au juge, sous le contrôle duquel s'exercent ces pouvoirs de police, de tenir compte, dans son appréciation, des nécessités provenant de l'état de guerre, selon les circonstances de temps et de lieu, la catégorie des individus visés et la nature des périls qu'il importe de prévenir;

Cons. qu'au cours de l'année 1916, les conditions dans lesquelles les agissements des filles publiques se sont multipliés à Toulon ont, à

(16) CE, 28 février 1919, Dames Dol et Laurent, Rec. Lebon p. 208.

(17) CE, 28 juin 1918, Heyriès, Rec. Lebon p. 651. 
raison tant de la situation militaire de cette place forte que du passage incessant des troupes à destination ou en provenance de l'Orient, présenté un caractère tout particulier de gravité dont l'autorité publique avait le devoir de se préoccuper au point de vue tout à la fois du maintien de l'ordre, de l'hygiène et de la salubrité et aussi de la nécessité de prévenir le danger que présentaient pour la défense nationale la fréquentation d'un personnel suspect et les divulgations qui pouvaient en résulter; qu'il est apparu que les mesures faisant l'objet du présent pourvoi s'imposaient pour sauvegarder d'une manière efficace tout à la fois la troupe et l'intérêt national."

On sait que l'ordre public, traditionnellement puis aujourd'hui, par application de l'article L. 2212-2 du Code général des collectivités territoriales, concerne trois objets distincts: la tranquillité publique, la sécurité et la salubrité publique.

La préservation de la santé, autant que la sécurité nationale, justifient donc les mesures exceptionnellement prises qui limitent la liberté individuelle des administrés.

De même, la Constitution permet les atteintes aux libertés publiques dans des situations aggravées. L'article 16 de la Constitution permet de conférer au Président de la République, pour la sauvegarde de la nation des pouvoirs exceptionnels.

"Lorsque les institutions de la République, l'indépendance de la nation, l'intégrité de son territoire ou l'exécution de ses engagements internationaux sont menacées d'une manière grave et immédiate et que le fonctionnement régulier des pouvoirs publics constitutionnels est interrompu, le président de la République prend les mesures exigées par ces circonstances, après consultation officielle du premier ministre, des présidents des assemblées ainsi que du Conseil constitutionnel.

Il en informe la nation par un message.

Ces mesures doivent être inspirées par la volonté d'assurer aux pouvoirs publics constitutionnels, dans les moindres délais, les moyens d'accomplir leur mission. Le Conseil constitutionnel est consulté à leur sujet.

Le Parlement se réunit de plein droit.

L'Assemblée nationale ne peut être dissoute pendant l'exercice des pouvoirs exceptionnels."

II apparaît certainement audacieux d'évoquer les pouvoirs exceptionnels de l'article 16 dans le cadre de la sauvegarde de la santé. Le constituant de 1958, à l'évidence, ne visait absolument pas les périls sanitaires mais bien l'état de guerre éventuel, notamment dans le cadre des conflits de décolonisation qui étaient à l'époque en cours. 
Malgré ce détournement évident de l'esprit de la Constitution, il demeure cependant possible de considérer en premier lieu que, conformément au texte, la continuité des institutions de la République pourrait très bien être menacée en cas d'épidémie, et notamment dans le cadre d'une guerre bactériologique, fut-elle terroriste.

De plus, comme pour tout régime conférant des prérogatives dérogatoires à l'autorité publique, c'est toujours la même idée de circonstances exceptionnelles qui permet de prendre des mesures exceptionnelles. Or par exception il convient d'entendre ici contraire aux libertés publiques.

Le but toutefois de ces dispositifs consiste précisément, malgré les atteintes, à assurer la préservation de l'Etat de droit. Celui-ci doit être impérativement conservé et les autorités publiques n'agissent donc que sur habilitation d'un texte particulier.

Un autre régime correspond à cette logique, figurant dans la loi du 3 avril 1955, initialement prévue pour remédier aux troubles en Algérie, et récemment utilisée en novembre 2005 pour mettre un terme aux "violences urbaines", puis prorogée et non censurée par le Conseil d'État, et qui permet au Président de déclarer l'État d'urgence par décret en Conseil des ministres.

“l'état d'urgence peut être déclaré sur tout ou partie du territoire métropolitain ou des départements d'outre-mer, soit en cas de péril imminent résultant d'atteintes graves à l'ordre public, soit en cas d'évènements présentant, par leur nature et leur gravité, le caractère de calamité publique".

Parmi les pouvoirs impliqués, le Ministre de l'Intérieur peut donc assigner à résidence toute personne "dont l'activité s'avère dangereuse pour la sécurité et l'ordre public".

Enfin, il apparaît nécessaire de rappeler l'existence de pouvoirs dérogatoires attribués au Ministre en charge de la santé en cas de péril sanitaire grave.

Les articles L. 3110-1 et suivants du Code de la santé publique édictent ainsi un régime totalement dérogatoire du droit commun permettant la création de nombreuses atteintes aux libertés des citoyens, dans le seul but de préserver la santé publique.

Cette suite d'articles est intéressante, en ce qu'elle est placée dans un titre relatif à la "surveillance épidémiologique". Elle compose de plus un chapitre préliminaire intitulé "Menace sanitaire grave". La messe doit donc être dite.

L'article L. 3110-1 du Code de la santé publique dispose ainsi que:

"En cas de menace sanitaire grave appelant des mesures d'urgence, notamment en cas de menace d'épidémie, le ministre chargé de la santé peut, par arrêté motivé, prescrire dans l'intérêt de la santé publique toute mesure proportionnée aux risques courus et appropriée aux 
circonstances de temps et de lieu afin de prévenir et de limiter les conséquences des menaces possibles sur la santé de la population".

Les établissements de santé sont ensuite invités à participer à ces mesures puisque l'article L. 3110-7 du même Code prévoit què:

"Chaque établissement de santé est doté d'un dispositif de crise dénommé plan blanc d'établissement, qui lui permet de mobiliser immédiatement les moyens de toute nature dont il dispose en cas d'afflux de patients ou de victimes ou pour faire face à une situation sanitaire exceptionnelle."

Si les Plans Blancs sont toutefois inefficaces, l'article L. 3110-8 rappelle pour sa part que:

"Si l'afflux de patients ou de victimes où la situation sanitaire le justifient, le représentant de l'État dans le département peut procéder aux réquisitions nécessaires de tous biens et services, et notamment requérir le service de tout professionnel de santé, quel que soit son mode d'exercice, et de tout établissement de santé ou établissement médicosocial dans le cadre d'un dispositif dénommé plan blanc élargi.

Ces réquisitions peuvent être individuelles ou collectives. Elles sont prononcées par un arrêté motivé qui fixe la nature des prestations requises, la durée de la mesure de réquisition ainsi que les modalités de son application. Le représentant de l'État dans le département peut faire exécuter d'office les mesures prescrites par cet arrêté.

L'indemnisation des personnes requises et des dommages causés dans le cadre de la réquisition est fixée dans les conditions prévues par l'ordonnance $n$. 59-63 du 6 janvier 1959 relative aux réquisitions de biens et de services."

Précisons que cette disposition est heureusement complétée par un texte spécifique du Code de la propriété intellectuelle qui autorise le Ministre en charge de l'Industrie à violer tous les brevets déposés en cas de menace à la santé publique notamment.

Les menaces graves à la santé équivalent de plus à une cause d'exonération de toute responsabilité pour les professionnels de santé, les dommages des actes réalisés étant indemnisés par la solidarité nationale.

Si les équipes sanitaires ne sont pas préparées, le juriste lui est parfaitement équipé pour valider la renonciation à toutes les libertés publiques.

C'est un travers d'ailleurs du positivisme de constater que si l'ordonnancement juridique est respecté, les atteintes sont justifiées, renouvelant en quelque sorte l'éternel débat entre légalité et légitimité.

C'est en définitive le cœur de la problématique: les situations d'urgence n'intéressent pas tellement le juriste quant aux pouvoirs pouvant être mis en œuvre. 


\section{II - LA COMPARAISON DE DEUX EXEMPLES: LE HIV ET L'EPIDEMIE DE GRIPPE AVIAIRE}

Deux exemples permettent de comprendre l'adaptation du dispositif de lutte contre les menaces sanitaires selon l'origine différente de cette menace. L'histoire de la lutte contre l'épidémie de $\mathrm{VIH}$ et la pandémie grippale (A), du fait de leur mode de contamination spécifique, possèdent des effets fortement différenciés (B).

\section{A - Les dispositifs de lutte}

Alors que le dispositif de lutte contre la pandémie grippale démontre la nécessité des atteintes aux libertés publiques (2), I'histoire de la lutte contre le VIH impose de rappeler le renforcement des libertés ayant été mis en $œ u v r e$ au bénéfice des personnes malades (1).

\section{Le dispositif de lutte contre le VIH}

Que dire sur la lutte contre la VIH qui n'a pas été dit en France et dans le monde? Cette pandémie est parfaitement documentée, répertoriée et surveillée par de nombreuses institutions sanitaires, spécialisées ou non, nationales ou internationales ${ }^{(18)}$.

(18) Pour une bibliographie non exhaustive v. not. Pour une anthropologie de l'épidémie, v. J.-P. Baud, SIDA et liberté. La régulation d'une épidémie dans un État de droit (ss. dir.), E. Heilmann, Actes Sud, 1991; Pour les problèmes de contaminations post-transfusionnelles: Y. Lambert-Faivre, L'indemnisation des victimes post-transfusionnelles du sida: hier, aujourd'hui et demain ..., RTD civ. 1993, p. 1; M.-D. Gmerk, Histoire du sida, début et origine d'une pandémie actuelle, Plon, 1989; M. Lucas, Transfusion sanguine et sida en 1985, Rapp. IGAS, septembre 1990; D.-C. Lambert, Le coût mondial du sida, CNRS., 1992; J. Foyer et L. Khaïat (ss dir.), Droit et sida: comparaison internationale, CNRS, 1994; J.-C. Thoenig et M. Setbon, L'action collective organisée face au risque: d'un cadre conceptuel au cas risque-sida, CNRS, 1995; C. Manuel, J.-L. San Marco, Sida: les enjeux éthiques, Doin, 1994; M.-A. Hermitte, Le sang et le droit: essai sur la transfusion sanguine, Seuil, 1996. Pour la responsabilité sanitaire: D. Berra, Responsabilités, indemnisation des dommages du sida. Action et rech. soc. octobre-décembre 1989; H. Margeat, Séropositivité, sida et jurisprudence, Gaz. Pal. 13 octobre 1991, p. 6; P. Jourdain, Responsabilité civile et contamination par le virus du sida à la suite de transfusions, RTD civ. 1992, p. 117; C. Delpoux, Contamination par transfusion sanguine: jurisprudence, loi et assurance, RGAT. 1992.25; M.-L. Morançais-Demeester, Contamination par le virus du sida: responsabilité et indemnisation, D. 1992, chron. p. 189; A. Holleaux, Transfusion sanguine, séropositivité et indemnisation des préjudices résultant de la contamination par le virus du sida, RD sanit. soc. 1992, p. 555; C. Debouy, La responsabilité de l'administration française du fait de la contamination par le virus du sida, JCP 1993, I, 3646 ; L. Dubouis, Sida et transfusion sanguine: l'assouplissement des conditions classiques de mise en jeu des professions de santé, RD sanit. soc. 1991, p. 574 ; F. Memmi, Sida et responsabilité civile, Gaz. Pal. 25 avril 1993, p. 2; H. Margeat, Sang et droit: l'indemnisation des victimes, Gaz. Pal. 6-7 août 1993, p. 2 ; F.-J. Pansier, Transfusion et religion, Gaz. Pal. 11-12 janvier 1995, p. 24; C. Rousseau, L'évaluation médico-légale en droit commun du dommage en rapport avec une séropositivité HIV., Rev. fran. domm. corp. 1993-3, p. 311; J.-S. Bergé, Risque et faute dans la contamination post-transfusionnelle, Gaz. Pal. 12-13 juillet 1996, p. 13; S. Gromb, Les problèmes médicaux légaux 
Trois exemples démontrent, pour le $\mathrm{VIH}$, la faveur dont les patients ont, au moins pour la protection juridique, bénéficié.

En premier lieu, et contrairement à des dispositifs encore récemment qualifiés de "fléaux sociaux" par le législateur, notamment l'alcoolisme, les maladies mentales, la tuberculose ou les syphilis, le VIH n'a jamais fait l'objet d'un traitement obligatoire.

De plus, l'article L. 1111-2 du Code de la santé publique rappelle que “La volonté d'une personne d'être tenue dans l'ignorance d'un diagnostic ou d'un pronostic doit être respectée, sauf lorsque des tiers sont exposés à un risque de transmission". La personne peut donc ne pas être tenue informée de sa pathologie, sur sa demande expresse, mais pour autant qu'aucun risque de contamination d'un tiers n'expose ce dernier à un danger.

En cette situation, le tiers ne bénéficie cependant d'aucune information puisque c'est la personne malade et elle seule - notamment du fait de l'obligation pénale du maintien du secret médical - qui sera informée. Le tiers demeure donc exposé au risque de contamination selon la volonté univoque de la personne malade.

Enfin, différents dispositifs prévoient, qu'ils soient d'ailleurs législatifs ou conventionnels, l'obligation de maintien de la possibilité, pour les personnes atteintes de maladies graves - le VIH en tête - de bénéficier d'une assurance.

La pandémie grippale au contraire révèle un ensemble de prérogatives nettement plus coercitives à la disposition des autorités publiques dans la mise en œuvre de la lutte.

\section{Le Plan de lutte contre la pandémie grippale}

Le Gouvernement diffuse sur un site Internet la totalité du plan prévu pour lutter efficacement contre le développement d'une pandémie grippale ${ }^{(19)}$.

II doit, schématiquement, être constaté que différents degrés de mise en œuvre apparaissent dans ledit Plan, au regard de l'importance de la menace et de ses effets attendus ou présents.

Ainsi, des mesures de surveillance sont d'abord prévues, épidémiologiques, mais aussi des oiseaux sauvages ou d'élevages. Ensuite, en cas de menace, des mesures de confinements d'élevages peuvent être ponctuellement et localement prononcées, de même que des restrictions à la vente.

de la transfusion sanguine, ESKA, 1997; M. Lebeau, Responsabilité et contaminations posttransfusionnelles, Gaz. Pal. 16-17 juin 1999, p. 35; C. Moniollet, Responsabilité et indemnisation à l'égard des personnes contaminées par le virus du sida lors de transfusions sanguines, RD sanit. soc. 1999 , p. 91.

(19) REPUBLIQUE FRANÇAISE. Disponivel em: <http://www.grippeaviaire.gouv.fr/>. 
De plus, toutes les personnes ayant été mises en contact avec les oiseaux porteurs ou potentiellement porteurs du virus $\mathrm{H} 5 \mathrm{~N} 1$ peuvent faire l'objet de restrictions à la circulation.

Puis, progressant dans la menace et les dangers, dès lors qu'un oiseau est contaminé au sein d'un élevage, il est possible de prononcer la destruction de ce dernier, en violation du droit de propriété, puis la destruction des cadavres. L'animal est évidemment, et par application univoque du Code civil, traité comme une chose, mais il est, en cette hypothèse, traité comme un produit et non plus comme un être vivant. Par anticipation d'un risque, l'élevage entier, même sain, peut ainsi être éradiqué.

En situation de danger pour l'homme ensuite, un traitement automatique, sur décision du ministre de la santé des personnes en contact avec les volailles peut être imposé. II sera constitué de prélèvements, traitements "thérapeutiques", suivi des patients et distribution des kits de prévention, mais sans obligation de les porter.

Enfin, continuant dans la gradation des atteintes aux libertés publiques, en situation de crise, des mesures de réquisitions de médecins retraités, réquisitions d'étudiants en médecine peuvent être prononcées afin de faire face au surcroît d'activité, de même que toutes restrictions à la liberté d'aller et venir. Des stratégies de soins privilégiées sont mises en œuvre au travers notamment du traitement prioritaire de certaines personnes, telles que le personnel des installations dont l'interruption présente un danger (centrales nucléaires, chimiques, etc.), le personnel soignant et toute personne participant à la préservation des fonctions militaires et stratégiques de la Nation.

Il apparaît ainsi aisé de constater la différence de traitement des deux épidémies.

\section{B - Une lutte différenciée}

La différence de traitement juridique de ces deux épidémies peut être triplement justifiée.

D'abord, si la prévention contre le VIH a fonctionné, c'est incontestablement du fait de l'adhésion des populations. II incombe ainsi aux autorités publiques de préserver le choix de l'individu et éviter, à tout prix de mettre en exergue un quelconque caractère infamant ou dévalorisant d'une telle contamination. L'échec précoce de la prévention peut notamment trouver à s'expliquer du fait du réel ostracisme subi par les premières victimes.

Pour la pandémie de grippe aviaire au contraire, le caractère foudroyant attendu de la contamination, l'impossibilité de prévoir des modes de protection et l'inutilité du recours à la bonne volonté de chacun justifient la création possible de mesures coercitives. 
Le mode de contamination respectif de ces deux maladies correspond, dans un premier cas, à une tentative de mise en exergue de la responsabilité individuelle de chacun et de la prise en compte de certains changements de comportement individuel pour, dans le second cas, prévenir à l'inverse une transmission contre laquelle tous les moyens disponibles sont inefficaces.

Il convient ensuite de constater l'analyse de la proportionnalité conduite dans les deux situations. Dans tous les cas, l'intérêt individuel est immanquablement sacrifié au profit de la préservation du bien public.

Qu'il s'agisse de la destruction d'un élevage pour un professionnel, qui constitue un préjudice économique énorme, ou de l'interdiction de traitement à l'hôpital en cas de pandémie sévère, le Gouvernement tente de maintenir une balance effective entre deux logiques contradictoires.

Enfin, si les stratégies demeurent bien différenciées en raison de modes de contamination profondément distincts, il semble que, dans les deux cas, une réflexion juridique demeure nécessaire.

Toutes ces situations d'épidémie consistent en effet, comme déjà observé, à permettre la remise en cause des principes de légalité. La caractéristique première de l'état d'exception réside exactement dans une telle remise en cause.

Il convient donc de déterminer, dans tous les cas, les limites de la nécessité des mesures imposées car, si les apparences de la légalité sont préservées par la création de régimes spéciaux, il n'en demeure pas moins que la démocratie impose aussi le maintien de certaines libertés fondamentales.

L'analyse de ces régimes dérogatoires opère donc une confusion entre le maintien de la société d'une part et la préservation de l'ordre démocratique d'autre part. Une balance certainement difficile à mettre en œuvre lors des situations de crise. 